\title{
Vitiligo on tribal mark: A demostration of Wolf's isotopic response
}

\section{Mufutau Muphy Oripelaye, Olaniyi Onayemi, Olayinka Abimbola Olasode, Fatai Olatunde Olanrewaju}

\author{
Department of Dermatology, Obafemi Awolowo University, Ile-Ife, Osun state, Nigeria
}

Corresponding author: Dr. Mufutau Muphy Oripelaye, E-mail: mmoripe@yahoo.co.uk

\begin{abstract}
Background: Wolf's isotopic response is the development of new lesions on old scar. Although this phenomenon is uncommon, most of the reported cases have been associated with development new lesions on the previously healed scar of herpes zoster infections. Case Report: Our patient is 74 year old woman with generalized vitiligo who demonstrated Wolf's isotopic response by developing new lesions of vitiligo along the track of old scar (tribal mark). Conclusion: The exhibition of Wolf's Isotopic response on old tribal mark, may transform a benign, asymptomatic tribal mark into a clinically significant feature which may aid the diagnosis of vitiligo.
\end{abstract}

Key words: Vitiligo; Wolf's isotopic response; Tribal mark

\section{INTRODUCTION}

Koebner phenomenon is the development of new lesions in a normal skin following injury and it is a welldocumented feature of vitiligo [1]. The appearance of a new skin disease on a healed scar of an old lesion known as Wolf's Isotopic response are not frequently reported. We present a 74 year old woman who presented with features of Wolf's Isotopic response by the development of vitiligo on tribal mark.

\section{CASE REPORT WOLF'S PHENOMENON}

We present a 74year old Nigeria woman of Yoruba extraction. She presented with a complain of generalize loss of skin colour (depigmentation) of 2 years duration. The skin depigmentation was notice on the face, the upper and the lower limbs as well as the trunk. The depigmentation has been increasing in severity from the time it was first noticed 2 years ago.

The patient was otherwise well except for the cosmetic distress cause by depigmentation. There is no history of associated fever, no history of oral ulcer or genital ulcer. She has no present or past history of shingles, and no associated autoimmune disease was found in the patient. She has never handle nor worked with chemicals known to cause skin depigmentation. There is no history of facial itching upon application of any cosmetic product. She is not known to react to any cosmetic product.

She was born to Yoruba parents 74 years ago and as part of the prevailing cultural practices at time, she had a tribal incision on her cheeks. She had lived all her life with the tribal marks on her face and has come to accept it as part of her identity. The scar has expectedly been asymptomatic. However, 2 years ago, with the onset of generalize depigmentation, similar depigmentation has also developed along the line of the scar, sparring other parts of the face. Examination of her skin shows symmetrical depigmentations involving the upper and lower limbs as well as trunk. A track of depigmented macules was observed on the two inferiorly located scarification mark (tribal mark) of both cheeks.

Her blood sugar including the fasting blood sugar and two hour post prandial were within normal limit. She

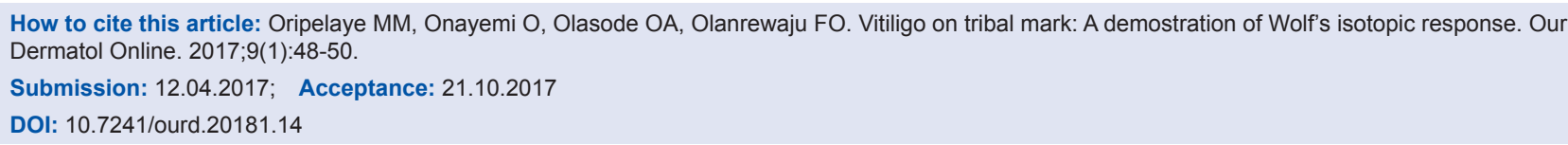


was seronegative for HIV, Hepatitis B infection and hepatitis $\mathrm{C}$ infection. The VDRL was also negative.

The assessment of generalize vitiligo was made and the demonstrated wolf's isotopic phenomenon observed in the scars of tribal mark was noted.

\section{DISCUSSION}

Vitiligo is an acquired disorder of pigmentation characterize by idiopathic loss of melanocyte. The melanocyte loss results in depigmented skin lesions associated with vitiligo. Useful but non-specific signs or phenomenon that may be used in the diagnosis of vitiligo is the Koebner phenomenon [1]. In addition to the koebner phenomenon which has been described in association with vitiligo, other variations that may be found includes trichrome vitiligo, which presents with overlapping areas of hypopigmentation, depigmented and normal coloured skin. Quadrichrome vitiligo which may also aid the diagnosis of vitiligo is the occurrence of perifolicular repigmentation in association with trichrome vitiligo [2].

Koebner phenomenon is the development of skin lesion following injury in a patient that has similar lesion in other part of the body [3]. Opinion varies on whether koebner phenomenon could impede the surgical management of vitiligo, since the associated surgical injury at the donor site can initiate new vitiligo lesion. However in the stable state it is believed such injury may not induce new lesions [4]. While inflicting injury could results in the development of new lesions, it can also lead to the clearance or healing of an existing skin lesion. This phenomenon known as reverse koebner has been described in psoriasis [3].

Also fascinating was the description of skin lesion on the site of a healed or old scar by Wolf et al. This description was termed wolf's isotopic response [5]. This response has been observed in few healed dermatological lesions. Mankesh et al reported development of herpes zoster on stable lesion of a vitiligo [6]. A track of depigmented macules was observed on the two inferiorly located scarification mark (tribal mark) of both cheeks (Figs. la and lb).

As in koebner phenomenon, the cause of Wolf's isotopic phenomenon is not known. However, viral induced neuroimmune dysfunction has been suggested because of the association of this phenomenon with herpes zoster. Other suspected causes are immune mediated,

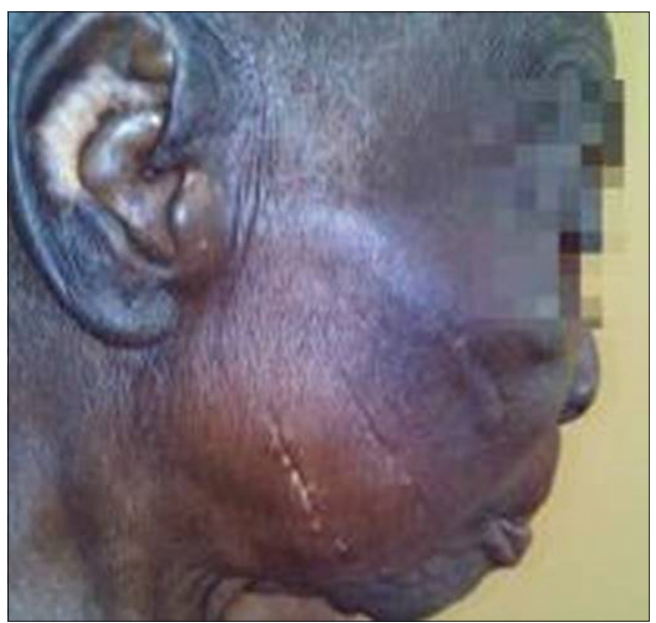

Figure 1a: A track of depigmentation on the inferior scars (tribal mark) of the right cheek.

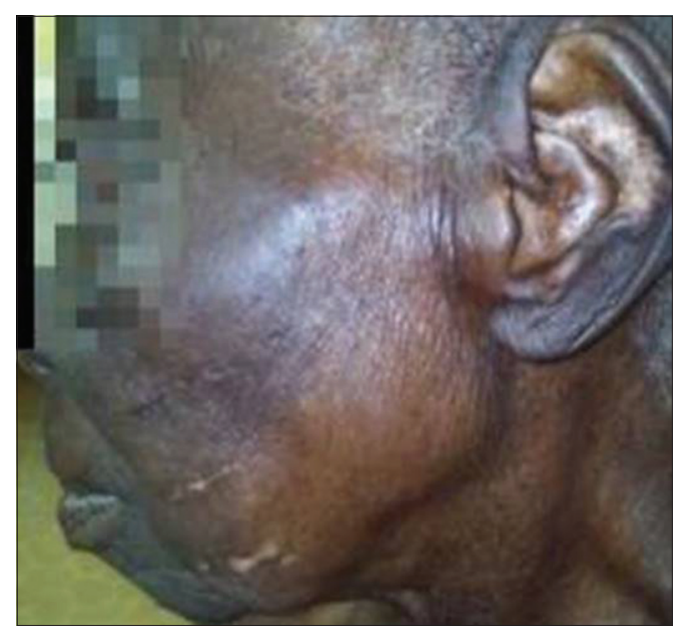

Figure 1b: A track of depigmentation on the inferior scars (tribal mark) of the left cheek.

neural and vascular dysfunction [5]. Most of the dermatoses which have been reported to demonstrate the wolf's isotopic phenomenon were related to the healed scars of herpes zoster infections [7]. However, in our patient, neither the healed scar (tribal mark) nor the developing lesions (vitiligo) were related to herpes zoster infection. The presence of the vitiligo on the scar of both cheeks also diminished the possibility of an association with herpes zoster which is likely to be dermatomal and unilateral. The healed scars of varicella, herpes simplex, scrofuloderma and striae distense have also been associated with wolf's isotopic response $[4,8]$. Our patient does present differently with the healed scar of a tribal mark.

While the cause of vitiligo is not known, viral theory has been suggested among the several theories proposed to explain its cause. Chronic hepatitis $\mathrm{C}$ infections and hepatitis B has been reported as in some patients 
with vitiligo [9]. Although these were not present in our patient. Other virus in the herpes group such as herpes simplex, cytomegalovirus and Ebsein-Barr virus although suspected, have not been satisfactorily established as cause of vitiligo $[9,10]$. While the presence of any of these viruses would have favoured virally induced neuroimmune dysfunction as a probable mechanism of the wolf isotopic phenomenon, none of these viruses were however identified in our patients.

\section{CONCLUSION}

The practice / culture of incising the checks has been on the decline, the impact of the scar (tribal mark) may be well beyond the cosmetic nuisance it caused in the patient since it may induce wolf isotopic phenomenon as depicted by our patient. Corroborating this observation with further studies will add clinical signs and phenomenon aiding the clinical diagnosis of vitiligo.

\section{REFERENCES}

1. Van Geel N, Speeckaert R, De Wolf J, Bracke S, Chevolet I, Brochez L, et al. Clinical significance of Koebner phenomenon in vitiligo. Br J Dermatol. 2012;167:1017-24.

2. Kovacs SO. Vitiligo. J Am Acad Dermatol. 1998;38:647-66.

3. Thappa DM. The isomorphic phenomenon of Koebner. Indian J Dermatol Venereo Leprol. 2004;70:187-9.

4. Mulekar SV, Asaad M, Ghwish B, Al Issa A, Al Eisa A. Koebner Phenomenon in Vitiligo: Not Always an Indication of Surgical Failure. Arch Dermatol. 2007;143:799-816.

5. Wolf R, Brenner S, Ruocco V, Filioli FG. Isotopic response. Int J Dermatol. 1995;34:341-8.

6. Lal Gambhir M, Pandey K, Kaur T. Herpes zoster on segmental vitiligo: isotopic response? Our Dermatol Online. 2014;5:155-6.

7. Shemer A, Weiss G, Trau H. Wolf's isotopic response: A case of zosteriform lichen planus on the site of healed herpes zoster. J Eur Acad Dermatol Venereol. 2001;15:445-7.

8. Requena L, Kutzner H, Escalonilla P, Ortiz S, Schaller JS, Rohwedders A. Cutaneous reactions at sites of herpes zoster scars: an expanded spectrum. Br J Dermatol. 1998;138:161-8.

9. Akcan Y, Kavak A, Sertbas Y, Olut AI, Korkut E, Bicik Z, et al. The low seropositivity of hepatitis B virus in vitiligo patients. J Eur Acad Dermatol Venereol. 2006;20:110-11.

10. Toker SC, Sarycaoglu H, Karadogan SK, Mistik R, Baskan $\mathrm{EB}$, Tunaly S. Is there any relation between vitiligo and cytomegalovirus? J Eur Acad Dermatol Venereol. 2007;21:141-2.

Copyright by Mufutau Muphy Oripelaye, et al. This is an open-access article distributed under the terms of the Creative Commons Attribution License, which permits unrestricted use, distribution, and reproduction in any medium, provided the original author and source are credited. Source of Support: Nil, Conflict of Interest: None declared. 